Article

\title{
Effect of MF-Coated Epoxy Resin Microcapsules on Properties of Waterborne Wood Coating on Basswood
}

\author{
Xiaoxing Yan ${ }^{1,2, *}$ and Yijuan Chang ${ }^{2}$ \\ 1 Co-Innovation Center of Efficient Processing and Utilization of Forest Resources, Nanjing Forestry \\ University, Nanjing 210037, China \\ 2 College of Furnishings and Industrial Design, Nanjing Forestry University, Nanjing 210037, China; \\ changyijuan@njfu.edu.cn \\ * Correspondence: yanxiaoxing@nuaa.edu.cn
}

Received: 1 July 2020; Accepted: 8 August 2020; Published: 12 August 2020

\begin{abstract}
In this paper, melamine-formaldehyde (MF) was used as the wall material, and epoxy resin was used as the core material to prepare microcapsules. The optical properties, mechanical properties and ageing resistance of waterborne topcoat were investigated by adding different mass fractions of microcapsules into the waterborne topcoat. Through scanning electron microscopy and infrared spectroscopy analysis, the prepared microcapsules of core-wall ratio of 0.50 were more uniform. It was found that when the mass fraction of microcapsules is less than $10.0 \%$ and the core-wall ratio is 0.50 , the original color difference of the coating can be maintained. With the increase in microcapsule mass fraction, the gloss of the topcoat film gradually decreases. The mass fraction of the microcapsule of $4.0 \%$ with the core-wall ratio of 0.50 can maintain the original gloss of $30.0 \mathrm{GU}$. The topcoat film with the MF-coated epoxy resin microcapsules of the core-wall ratio of 0.50 has high impact resistance, adhesion and hardness. The results showed that the gloss loss and color difference of the coating with the MF-coated epoxy microcapsules were the lowest when the mass fraction of microcapsules was $4.0 \%$, indicating that microcapsules can improve the stability of coating. These results lay a technical foundation for the development and application of high-performance wood coatings.
\end{abstract}

Keywords: microencapsulation; MF; epoxy resin; waterborne coating performance

\section{Introduction}

Microcapsules have attracted widespread attention because they have excellent properties to protect the core material from being changed by foreign objects. The core material covered by the wall material can not only shield the taste, color, odor, but also change the weight, volume, state, or surface properties of the substance. The wall material can control the slow release of the core material and separate incompatible substances [1] and even achieve the purpose of improving the actual useability of the material and improving the mechanical and optical properties [2]. Today, microcapsule technology has been used in more and more fields. In the wood coating process [3,4], the waterborne coatings can reduce VOC (volatile organic compound) emissions and are therefore more environmentally friendly $[5,6]$. Still, cracking defects are likely to occur in the coating and subsequent use process, resulting in reduced mechanical properties, so self-healing microcapsule technology can be used to repair the cracks [7]. Due to the expansion and drying shrinkage of wood substrate, when the surface coating on wood materials is cracked, the wall material will crack, and the core material will flow out the repair agent to fill the microcracks, thereby improving the durability of the paint film and extending the service life [8].

White et al. [9] prepared dicyclopentadiene microcapsules using urea-formaldehyde resin as the wall material by in-situ polymerization and took the lead in realizing the industrial application 
of self-healing material microcapsules. Song et al. [10] developed a system involving an extrinsic self-healing coating to identify cracked and healed regions by the yellow fluorescence and blue fluorescence, respectively. The healed regions were successfully detected under UV irradiation. Ataei et al. [11] verified the self-healing properties of microcapsules with vegetable oil as a healing agent in the surface coating of metallic materials. Taske et al. [12] calculated the diffusion coefficient by measuring the interfacial tension between the oil, polymer and water phases, thereby predicting the morphology of the microcapsules. However, the current experiments on microcapsules are rarely applied on the surface of wood.

Melamine-formaldehyde (MF) resin is a polymer made of melamine and formaldehyde and distilled water by heating and stirring. MF resin has good thermal stability, good sealing properties and boiling water resistance. The heat resistance and water resistance are better than those of urea formaldehyde resin [13]. The epoxy resin has the advantages of compactness [14], good water resistance [15], good leakage resistance [16] and high resistance to impact [17]. Basswood is a kind of common wood, which has the characteristics of oil resistance, wear resistance, corrosion resistance and non cracking. It also has the advantages of fine texture, easy processing and strong toughness. Basswood is widely used in wood crafts, musical instruments, furniture, etc.

In this paper, MF resin was used as the wall material, and epoxy resin was used as the core material. The MF-coated epoxy resin microcapsules were prepared by the in-situ polymerization method and added to the wood coating. The effects of MF-coated epoxy resin microcapsules on the adhesion, hardness, gloss and resistance to impact of wood coating on basswood were investigated. The purpose of the microcapsules prepared in this experiment was to repair the microcracks of wood coating in time, without reducing the performance of the coating, so as to reduce the deterioration probability of microcracks, prevent them from becoming visible defects, improve the safety of wood paint films, and prolong the service life, so as to provide technical reference for the application of self-healing technology.

\section{Materials and Methods}

\subsection{Materials}

Melamine (99.8\%, $M_{\mathrm{w}}: 126.12 \mathrm{~g} / \mathrm{mol}$, CAS No.: 108-78-1) was provided by Shandong Ysolf Chemical Technology Co., Ltd., Linyi, China. Formaldehyde solution ( $37.0 \%$, analytically pure, $M_{\mathrm{w}}$ : $30.03 \mathrm{~g} / \mathrm{mol}$, CAS No.: 50-00-0), benzyl alcohol ( $M_{\mathrm{w}}: 108.13 \mathrm{~g} / \mathrm{mol}$, CAS No.: 100-51-6) triethanolamine (analytical purity, $M_{\mathrm{W}}: 149.19 \mathrm{~g} / \mathrm{mol}$, CAS No.: 102-71-6), and anhydrous ethanol ( $M_{\mathrm{W}}: 46.07 \mathrm{~g} / \mathrm{mol}$, CAS No.: 64-17-5) were provided by Nanjing Chemical Reagent Co., Ltd., Nanjing, China. Bisphenol A liquid epoxy resin (E-51 solid concentration 99.6\%, industrial pure) was provided by Hangzhou Wuhuigang Adhesive Co., Ltd., Hangzhou, China. Sodium dodecylbenzene sulfonate (analytical purity, $M_{\mathrm{w}}: 348.48 \mathrm{~g} / \mathrm{mol}$, CAS No.: 25155-30-0) was provided by Tianjin Beichen Founder Reagent Factory, Tianjin, China. Citric acid $\left(M_{\mathrm{w}}: 192.13 \mathrm{~g} / \mathrm{mol}\right.$, CAS No.:77-92-9), provided by Tianjin Beilian Fine Chemical Development Co., Ltd., Tianjin, China. N-octanol ( $M_{\mathrm{w}}: 130.23 \mathrm{~g} / \mathrm{mol}$, CAS No.: 111-87-5) was provided by Wuxi Asia-Pacific United Chemical Co., Ltd., Wuxi, China.

Basswood (Tilia tuan Szyszyl, $100 \mathrm{~mm} \times 100 \mathrm{~mm} \times 5 \mathrm{~mm}, 600$ pieces, sanded by 400 mesh sandpaper) was supplied by Yihua Lifestyle Technology Co., Ltd., Shantou, China. Waterborne topcoat coating consisted of waterborne acrylic copolymer dispersion (the concentration was $90.0 \%$ ), matting agent (the concentration was $2.0 \%$ ), additives (the concentration was $2.0 \%$ ) and water (the concentration was $6.0 \%$ ). Waterborne topcoat coating was supplied by Yihua Lifestyle Technology Co., Ltd., Shantou, China.

\subsection{Preparation of MF-Coated Epoxy Resin Microcapsules and Coating}

The preparation of MF-coated epoxy resin microcapsules with a core-wall ratio of 0.50 was as follows. The $15.0 \mathrm{~g}$ of white melamine powder and $30.0 \mathrm{~g}$ of formaldehyde solution were put into 
a $250 \mathrm{~mL}$ beaker, $30.0 \mathrm{~mL}$ distilled water was added, and then triethanolamine was added to adjust the $\mathrm{pH}$ value to 8.5 9.0. The transparent plastic film was used to seal the beaker mouth, and then the milky white solution was put into the constant temperature water bath with the stirring device. The water temperature was adjusted to $70^{\circ} \mathrm{C}$ and the mixture was evenly stirred at a rate of $900 \mathrm{rpm}$ to ensure that the formaldehyde reacted with melamine. The solution was put in a water bath and heated and stirred for $50 \mathrm{~min}$. The color of the solution gradually changed from milky white to transparent to obtain a wall material MF prepolymer.

The $7.5 \mathrm{~g}$ of epoxy resin and $1.125 \mathrm{~g}$ of benzyl alcohol were added to a $250 \mathrm{~mL}$ clean beaker and stirred evenly. The $58.5 \mathrm{~g}$ of distilled water and $0.585 \mathrm{~g}$ of sodium dodecylbenzene sulfonate were mixed and stirred to prepare a $1.0 \%$ emulsifier solution and poured into the diluted epoxy resin solution. The beaker was transferred to a magnetic stirrer with constant temperature heating. The temperature of the water bath was $60^{\circ} \mathrm{C}$, and the stirring time was $45 \mathrm{~min}$. Finally, the defoamer $\mathrm{n}$-octanol solution was dropped into a small amount to obtain a stable core material emulsion. The core material emulsion was stirred at $800 \mathrm{rpm}$, and the MF prepolymer was slowly dripped into the core material emulsion. Citric acid crystals were added to the mixed solution, the $\mathrm{pH}$ was adjusted to $4.0 \sim 5.0$, and the reaction was carried out at $70^{\circ} \mathrm{C}$ for $3 \mathrm{~h}$. Left at room temperature for 5 days, the mixed solution was suction-filtered using a circulating water multi-purpose vacuum pump, and the precipitate was washed with distilled water and absolute ethanol, and then placed in a $40^{\circ} \mathrm{C}$ oven for heating and drying for $48 \mathrm{~h}$. The preparation of microcapsules with a core-wall ratio of 0.67 changes the core material ratio. The preparation process was the same as above.

\subsection{Preparation of Coating}

Basswoods were placed at room temperature, the relative temperature was $50.0 \pm 5.0 \%$, and the humidity was kept for one week to make the substrate reach the equilibrium moisture content $(14.9 \%$, in Nanjng, China). Two kinds of core-wall ratio microcapsules were added into the waterborne topcoat coating at the mass fractions of $0 \%, 1.0 \%, 4.0 \%, 7.0 \%, 10.0 \%, 13.0 \%, 16.0 \%$ and $20.0 \%$, stirred with the magnetic stirrer at $100 \mathrm{rpm}$ for $30 \mathrm{~min}$ to mix evenly and then applied on basswood with $150 \mathrm{~g} / \mathrm{m}^{2}$. The microcapsules did not break. Table 1 shows the ingredients of topcoat paint film with different mass fractions of microcapsules. Taking 1.0\% microcapsule as an example, the coating on basswood substrate was coated by SZQ tetrahedron applicator (Tianjin Jinghai Science and Technology Testing Machinery Factory, Tianjin, China). The topcoat film was dried in air at room temperature for $30 \mathrm{~min}$, transferred to an electric blast drying oven at $40{ }^{\circ} \mathrm{C}$, heated to the same mass, and then cooled to room temperature naturally. Then, the coating was gently ground with 800 mesh sandpaper and wiped with dry cloth to remove the dust on the surface. After repeating this process twice, the topcoat coating process was completed. Other mass fractions of microcapsules in waterborne topcoat coating refer to the preparation method of microcapsules with 1.0\% mass fraction. The dry film thickness of waterborne wood coating is about $60 \mu \mathrm{m}$.

Table 1. Topcoat film ingredients table with different microcapsule mass fractions.

\begin{tabular}{cccc}
\hline $\begin{array}{c}\text { Microcapsule Mass } \\
\text { Fraction (\%) }\end{array}$ & $\begin{array}{c}\text { Microcapsule Weight } \\
(\mathbf{g})\end{array}$ & $\begin{array}{c}\text { Waterborne Topcoat } \\
\text { Weight (g) }\end{array}$ & $\begin{array}{c}\text { Microcapsule } \\
\text { Waterborne Coating } \\
\text { Weight (g) }\end{array}$ \\
\hline 0 & 0 & 3.00 & 3.00 \\
1.0 & 0.03 & 2.97 & 3.00 \\
4.0 & 0.12 & 2.88 & 3.00 \\
7.0 & 0.21 & 2.79 & 3.00 \\
10.0 & 0.30 & 2.70 & 3.00 \\
13.0 & 0.39 & 2.61 & 3.00 \\
16.0 & 0.48 & 2.52 & 3.00 \\
20.0 & 0.60 & 2.40 & 3.00 \\
\hline
\end{tabular}




\subsection{Testing and Characterization}

A tapered hole with an apex angle of $120^{\circ}$ was drilled in the coating, and the hole wall was imaged with a microscope with a $40 \times$ magnification. The part of the busbar coating perpendicular to the microscope axis was read. The length of the coated part of the busbar was measured. According to the trigonometric function relationship, the coating thickness was half the length of the busbar coating part. The three-point arithmetic average method was used to evaluate the thickness of the waterborne topcoat paint for the three spots.

The microstructure of the microcapsules and topcoat film was tested by Quanta 200 environmental scanning electron microscope (SEM), FEI Company (Hillsboro, OR, USA). The samples adhered to the sample pedestal, and the appropriate time and voltage of gold plating were set for gold plating. After the gold plating was finished, the samples were taken out and placed in the sample chamber. When the vacuum degree reached a certain value, the pressure was increased and the SEM of the samples was observed. The acceleration voltage of SEM was $200 \mathrm{~V}-30 \mathrm{kV}$, the magnification was 20-300,000 times, and the resolution was $3.5 \mathrm{~nm}$. The dimension of the microcapsules was analyzed using a L2800 Biomicroscope, Guangzhou Liss Optical Instrument Co., Ltd. (Guangzhou, China). The chemical composition of the topcoat film was analyzed by VERTEX $80 \mathrm{v}$ infrared spectrometer, Germany BRUKER Co., Ltd., Karlsruhe, Germany. The coating on the wood surface was made using the attenuated total refraction (ATR) method. The samples were placed above the ATR accessory to make the samples come into close contact with the ATR crystal. The infrared beam attenuated and reflected in the ATR crystal (diamond) and reached the detector.

The color difference of the topcoat film was measured using SEGT-J portable color difference meter (Zhuhai Tianchuang Instrument Co., Ltd., Zhuhai, China). $L^{*}$ represents the lightness, and the large value means the surface color of the measured object is bright. The $a^{*}$ represents the change of color from red to green, the positive value means a reddish color, and the negative value means greenish. The $b^{*}$ represents the change of color from yellow to blue, the positive value means that the surface color of the measured object is yellowish, and the negative value means it is blueish. $L_{1}{ }^{*}, a_{1}{ }^{*}$ and $b_{1}{ }^{*}$ are the chroma values of the coating sample without microcapsules, while $L_{2}{ }^{*}, a_{2}{ }^{*}$ and $b_{2}{ }^{*}$ are the chroma values of the coating sample with different mass fractions of microcapsules. $\Delta L^{*}$ (light difference) $=L_{1}{ }^{*}-L_{2}{ }^{*}, \Delta a^{*}$ (red-green difference) $=a_{1}{ }^{*}-a_{2}{ }^{*}, \Delta b^{*}$ (yellow-blue difference) $=b_{1}{ }^{*}-b_{2}{ }^{*}$. The total color difference was calculated according to the Formula (1) [18]:

$$
\Delta E=\left[\left(\Delta L^{*}\right)^{2}+\left(\Delta a^{*}\right)^{2}+\left(\Delta b^{*}\right)^{2}\right]^{1 / 2}
$$

The impact resistance of the topcoat film was tested by a QCJ impactor (Tianjin Jingkelian Material Testing Machine Co., Ltd., Tianjin, China). In the impact test, $1.0 \mathrm{~kg}$ ball falls freely from different heights (the maximum height is $50.0 \mathrm{~cm}$ ). After the ball fell on the surface of the coating, the damage of the coating was observed. The impact strength was the maximum height of the ball falling without damaging the coating. The adhesion of the topcoat film was tested by the QFZ-II coating adhesion tester (Tianjin JingKelian Material Testing Machine Co., Ltd., Tianjin, China). The topcoat film was cut at a uniform speed with uniform pressure. Then, the sample was rotated $90^{\circ}$ and repeatedly cut in the same area to form a pattern. Finally, the whole area was pasted with special transparent tape (pressure-sensitive adhesive tape, adhesive force $(10 \pm 1) \mathrm{N} / 25 \mathrm{~mm}$, width greater than $50 \mathrm{~mm}$ ), and then the tape was peeled off. The magnifying glass was used to observe whether the paint film on the surface was separated from the substrate. The Chinese brand 101 drawing pencil (China first Pencil Co., Ltd., Shanghai, China) manufactured by GB/T26704-2011 was used to determine the hardness of the topcoat film according to the pencil method specified in the GB/T6739-2006 standard [19]. Different types of pencil with hardness from soft to hard were used to scratch the paint film, which were $6 \mathrm{~B}, 5 \mathrm{~B}, 4 \mathrm{~B}, 3 \mathrm{~B}, 2 \mathrm{~B}, \mathrm{~B}, \mathrm{HB}, \mathrm{H}, 2 \mathrm{H}, 3 \mathrm{H}, 4 \mathrm{H}, 5 \mathrm{H}, 6 \mathrm{H}$. The greater the number $\mathrm{B}$, the darker and softer the pencil. The greater the $\mathrm{H}$, the harder and lighter the color. $\mathrm{HB}$ is the middle. Whether the paint film was scratched or not was judged by magnifying glass, and the pencil model that could not scratch 
the topcoat film was used as the judgment standard. The gloss of the topcoat film was tested using a $3 \mathrm{NH}$ smart gloss meter (produced by 3NH Technology Co., Ltd., Shenzhen, China) [20]. The ageing and stability test was measured in a ZN ultraviolet ageing resistance tester (Nanjing Environmental Test Equipment Co., Ltd., Nanjing, China) for $240 \mathrm{~h}$. A mixture of rosin and paraffin was coated on the side and the back of the coated Basswoods, leaving a $10.0 \mathrm{~cm} \times 5.0 \mathrm{~cm}$ coating, and the samples were put in the ZN ultraviolet ageing resistance tester. The UV region was considered as $290-400 \mathrm{~nm}$ and the illumination level was $0.08 \mathrm{~W} / \mathrm{cm}^{2}$. All the experiments were repeated four times with an error of less than $5.0 \%$.

\section{Results and Discussion}

\subsection{Microcapsule Structure}

The MF-coated epoxy microcapsules with a core-wall ratio of 0.50 and 0.67 were observed by SEM, as shown in Figure 1. It was found that the microcapsules with both core-wall ratios were successfully coated. The microcapsules with 0.50 core-wall ratio are more uniform in size, the surface is smoother, and the diameter is about $5-10 \mu \mathrm{m}$. By comparison, the microcapsules with 0.50 of core-wall ratio were better than those with 0.67 of core-wall ratio, with a uniform size and smooth surface. Figure 2 shows the microscopic pictures of the MF-coated epoxy resin microcapsules. The wall thickness of microcapsules with a core-wall ratio of 0.50 and 0.67 were about 4.0 and $4.7 \mu \mathrm{m}$, respectively.
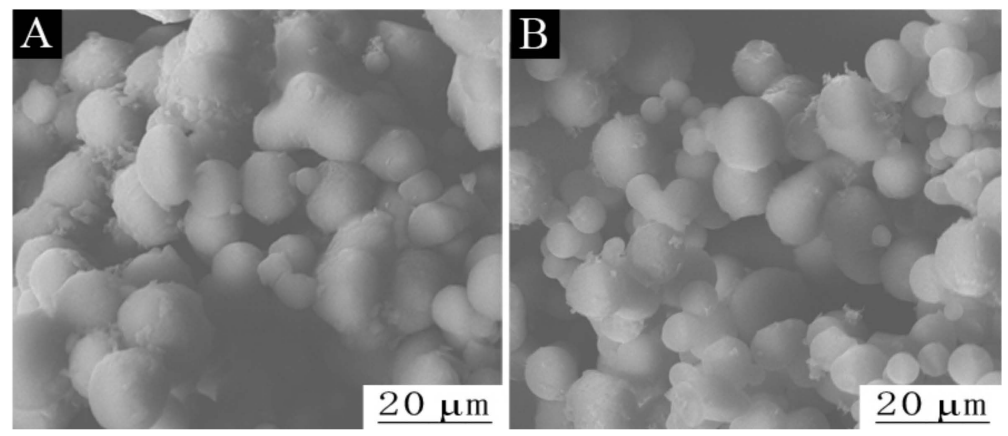

Figure 1. SEM images of the microcapsules with different core-wall ratios: (A) 0.67 and (B) 0.50 .
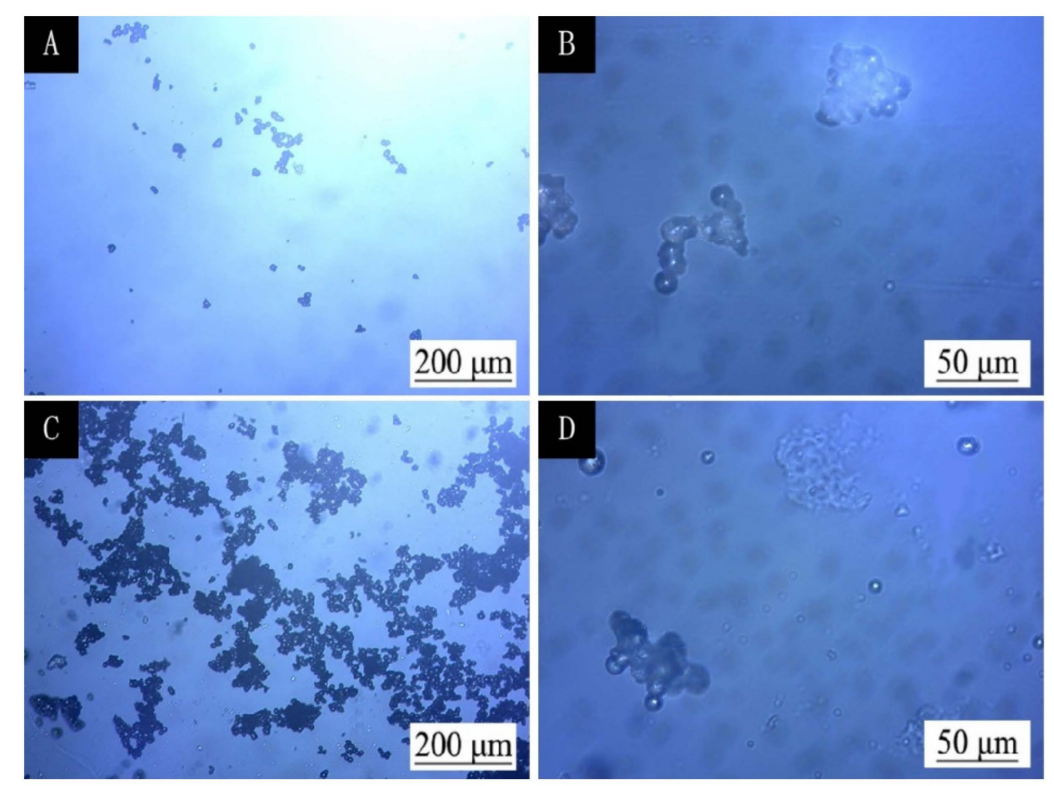

Figure 2. Microscopic pictures of the microcapsules with different core-wall ratios: (A,B) 0.67, (C,D) 0.50. 
Figure 3 is the infrared spectrum of the MF-coated epoxy resin microcapsules of 0.50 core-wall ratio and 0.67 core-wall ratio. The peaks at $3400,2970,1600$ and $1485 \mathrm{~cm}^{-1}$ are the stretching vibration peaks of the $\mathrm{N}-\mathrm{H}, \mathrm{C}-\mathrm{H}, \mathrm{C}=\mathrm{N}$, and $\mathrm{C}-\mathrm{N}$ bonds, respectively [21]. The 1153 and $976 \mathrm{~cm}^{-1}$ are the expansion vibrations of $\mathrm{C}-\mathrm{O}$ in epoxy resin [22]. The epoxy resin was liquid, and if it is not the core material of the microcapsule, it will be filtered out. The epoxy resin was coated by MF resin, which indicated that the preparation of the microcapsule was successful.

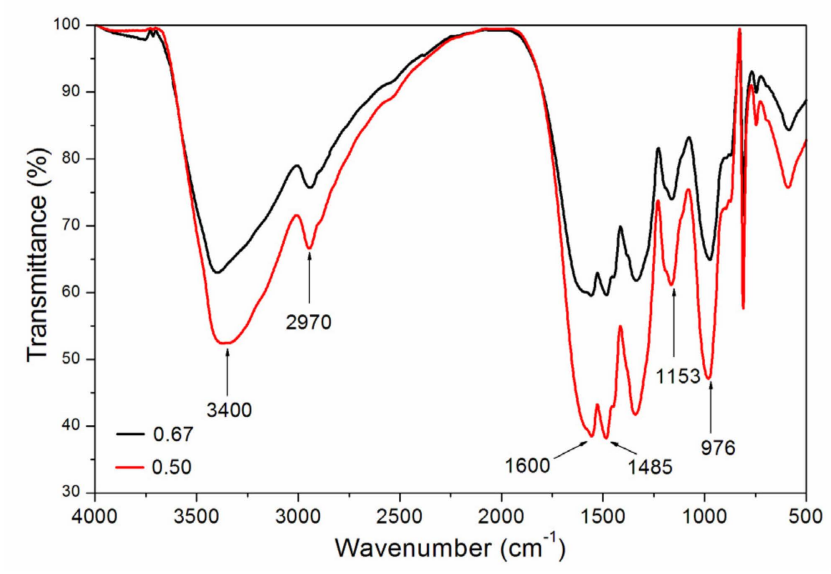

Figure 3. Infrared spectra of the 0.67 and 0.50 core-wall ratio microcapsules.

\subsection{Effect of Microcapsule Mass Fraction on Optical Properties}

It can be found from Figure 4 that as the mass fraction of microcapsules increases, the microcapsules are easy to agglomerate and are unevenly distributed in the coating. The waterborne coating with $4.0 \%$ microcapsule mass fraction is smoother and only a few particles were observed. The coating without microcapsules and the coating with $4.0 \%$ MF-coated epoxy resin microcapsules are smoother than those with $16.0 \%$ MF-coated epoxy microcapsules. The topcoat film with 0.50 core-wall ratio is smoother than that with 0.67 core-wall ratio. Compared with the coating without microcapsules, there is not much difference.

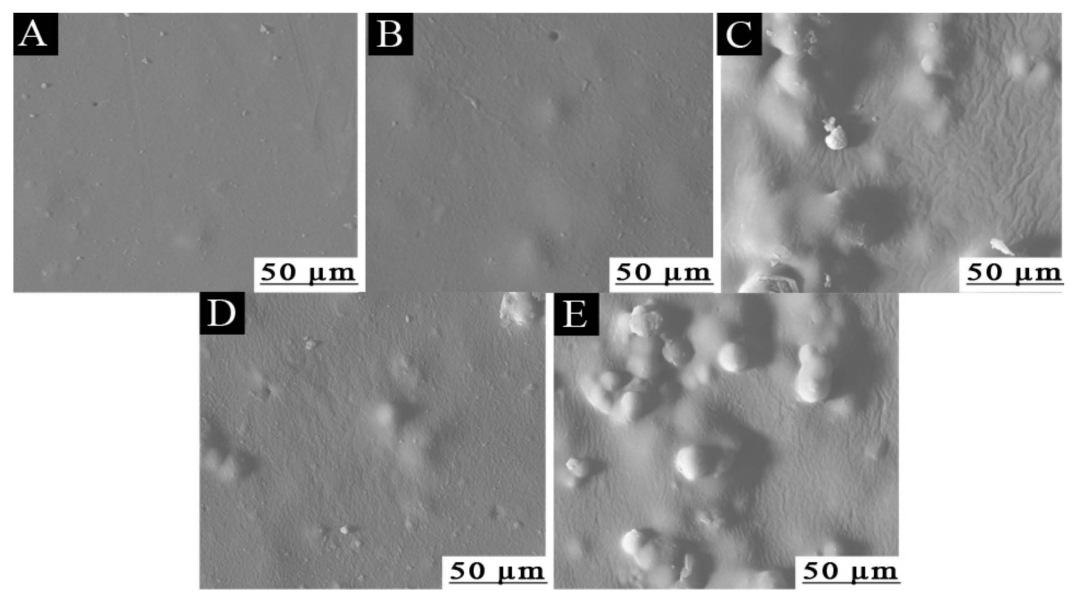

Figure 4. SEM images of the topcoat films with different microcapsule mass fractions: (A) topcoat; topcoat with (B) $4.0 \%$ and (C) $16.0 \%$ of 0.50 core-wall ratio microcapsules; topcoat with (D) $4.0 \%$ and (E) $16.0 \%$ of 0.67 core-wall ratio microcapsules.

It can be seen from Figure 5 that as the mass fraction of microcapsules increases, the color difference of the sample increases accordingly. It is due to the increase in the mass fraction of microcapsules. The coarseness and unevenness of the coating are increased after the particles are agglomerated. 
According to the range of color difference corresponding to the level of discoloration (Table 2), when the mass fraction of microcapsules is less than $10.0 \%$ and the core-wall ratio is 0.50 , the original color difference of the coating can be maintained, and the change is not obvious. Therefore, it is preliminarily proved that the MF-coated epoxy resin microcapsule can keep the original color of the coating. Figure 6 is a comparison diagram of the basswood and the coated basswood when the mass fraction of the microcapsules with a 0.50 core-wall ratio of $4.0 \%$. It can be seen that the coating is transparent and the wood texture is still very clear, and the color difference of coated basswood is more obvious than that without coating.

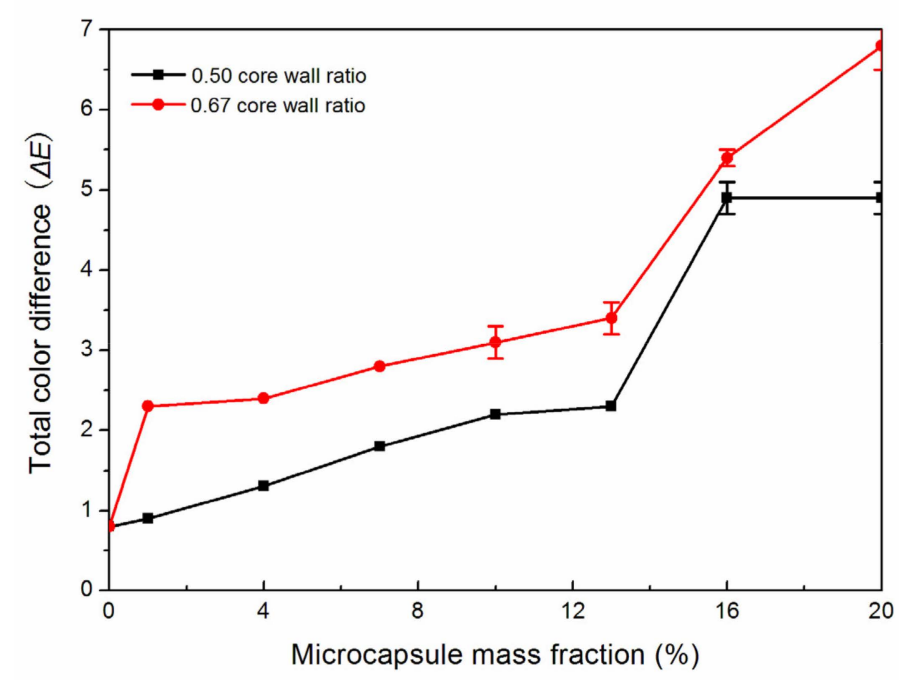

Figure 5. Change of the sample's total color difference the with different mass fractions.

Table 2. Range of color difference corresponding to the level of discoloration.

\begin{tabular}{ccc}
\hline Level & Degree of Discoloration & Color Difference \\
\hline 0 & no discoloration & $\leq 1.5$ \\
1 & very slight discoloration & $1.6-3.0$ \\
2 & slight discoloration & $3.1-6.0$ \\
3 & apparent discoloration & $6.1-9.0$ \\
4 & severe discoloration & $9.1-12.0$ \\
5 & complete discoloration & $>12.0$ \\
\hline
\end{tabular}
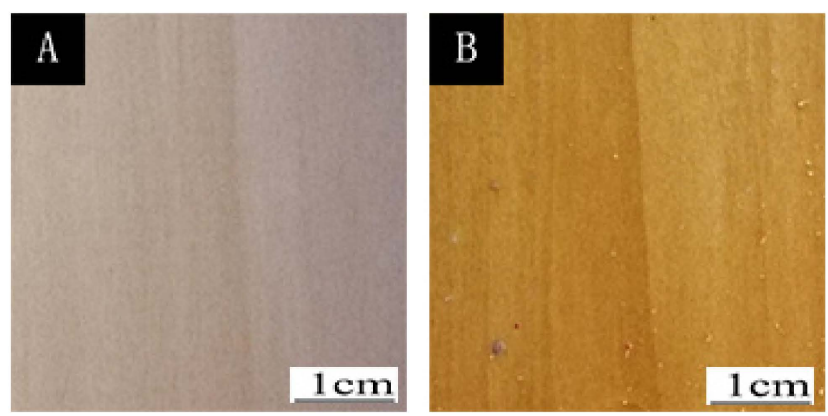

Figure 6. (A) Basswood; (B) coated basswood with $4.0 \%$ of the microcapsule with a 0.5 core-wall ratio.

The topcoat film was irradiated with different light incident angles, and the influence of different mass fractions of microcapsules on the gloss change of the topcoat film was observed. The incident angles of light used in this study were $20^{\circ}, 60^{\circ}$, and $85^{\circ}$. As shown in Table 3 , under the same intensity of incident light, as the mass fraction of MF-coated epoxy resin microcapsule increases, the gloss of the topcoat film gradually decreases. The main reason is that as the mass fraction of microcapsules 
increases, the number of microcapsule particles in the topcoat film increases, resulting in a reduction in light reflection [23]. The topcoat film containing an 4.0\% MF-coated epoxy resin microcapsule is relatively smooth, and the gloss of the topcoat film was prepared by adding 0.50 of core-wall ratio of the microcapsules is higher than that of the topcoat film with 0.67 of core-wall ratio of the microcapsules.

Table 3. Effect of microcapsule mass fraction on gloss of topcoat film.

\begin{tabular}{|c|c|c|c|c|c|c|}
\hline \multirow{2}{*}{$\begin{array}{c}\text { Microcapsule } \\
\text { Mass Fraction (\%) }\end{array}$} & \multicolumn{3}{|c|}{ 0.50 Core-Wall Ratio } & \multicolumn{3}{|c|}{0.67 Core-Wall Ratio } \\
\hline & $\begin{array}{c}20^{\circ} \text { Gloss } \\
(\text { GU) }\end{array}$ & $\begin{array}{c}60^{\circ} \text { Gloss } \\
\text { (GU) }\end{array}$ & $\begin{array}{c}85^{\circ} \text { Gloss } \\
\text { (GU) }\end{array}$ & $\begin{array}{c}20^{\circ} \text { Gloss } \\
\text { (GU) }\end{array}$ & $\begin{array}{c}60^{\circ} \text { Gloss } \\
\text { (GU) }\end{array}$ & $\begin{array}{l}85^{\circ} \text { Gloss } \\
\text { (GU) }\end{array}$ \\
\hline 0 & $8.4 \pm 0.2$ & $31.6 \pm 0.8$ & $48.9 \pm 1.2$ & $8.4 \pm 0.2$ & $31.6 \pm 0.8$ & $48.9 \pm 1.2$ \\
\hline 1.0 & $9.0 \pm 0.2$ & $31.2 \pm 0.8$ & $33.0 \pm 0.8$ & $8.3 \pm 0.2$ & $27.1 \pm 0.5$ & $26.5 \pm 0.5$ \\
\hline 4.0 & $7.3 \pm 0.2$ & $30.0 \pm 0.8$ & $19.3 \pm 0.6$ & $3.3 \pm 0.1$ & $16.8 \pm 0.4$ & $9.2 \pm 0.2$ \\
\hline 7.0 & $2.8 \pm 0.1$ & $15.1 \pm 0.4$ & $5.2 \pm 0.2$ & $3.7 \pm 0.1$ & $14.8 \pm 0.6$ & $5.7 \pm 0.2$ \\
\hline 10.0 & $2.6 \pm 0.1$ & $13.3 \pm 0.3$ & $4.3 \pm 0.2$ & $1.8 \pm 0.1$ & $7.2 \pm 0.2$ & $2.8 \pm 0.1$ \\
\hline 13.0 & $2.5 \pm 0.1$ & $7.9 \pm 0.2$ & $3.9 \pm 0.1$ & $1.7 \pm 0$ & $7.0 \pm 0.2$ & $1.3 \pm 0$ \\
\hline 16.0 & $1.9 \pm 0$ & $7.5 \pm 0.2$ & $1.9 \pm 0.1$ & $1.5 \pm 0$ & $4.9 \pm 0.2$ & $0.6 \pm 0$ \\
\hline 20.0 & $1.2 \pm 0$ & $2.7 \pm 0$ & $0.2 \pm 0$ & $1.3 \pm 0$ & $2.7 \pm 0$ & $0.2 \pm 0$ \\
\hline
\end{tabular}

\subsection{Effect of Microcapsule Mass Fraction on Mechanical Properties of Waterborne Topcoat Film}

The hardness test of the coating film refers to how strong the resistance of the topcoat film is when foreign objects invade the surface, and is an important indicator of the mechanical strength of the topcoat film [24]. The hardness of the topcoat film is shown in Table 4. When the mass fraction of the microcapsules is $4.0 \%-20.0 \%$, the hardness of the topcoat film with MF-coated epoxy resin microcapsules with a core-wall ratio of 0.50 is higher than that of the microcapsules with a core-wall ratio of 0.67 . It can be seen from Table 5 that as the mass fraction of the microcapsules increases, the impact resistance of the topcoat film increases, and the topcoat film with a 0.50 core-wall ratio has a greater impact resistance.

Table 4. Effect of the microcapsule mass fraction on the hardness of topcoat film.

\begin{tabular}{ccc}
\hline Microcapsule Mass Fraction (\%) & $\mathbf{0 . 5 0}$ Core-Wall Ratio & $\mathbf{0 . 6 7}$ Core-Wall Ratio \\
\hline 0.0 & $\mathrm{H}$ & $\mathrm{H}$ \\
1.0 & $\mathrm{HB}$ & $\mathrm{HB}$ \\
4.0 & $\mathrm{H}$ & $\mathrm{HB}$ \\
7.0 & $\mathrm{H}$ & $\mathrm{HB}$ \\
10.0 & $\mathrm{H}$ & $\mathrm{HB}$ \\
13.0 & $\mathrm{H}$ & $\mathrm{HB}$ \\
16.0 & $\mathrm{H}$ & $\mathrm{HB}$ \\
20.0 & $\mathrm{H}$ & $\mathrm{HB}$ \\
\hline
\end{tabular}

Table 5. Effect of the microcapsule mass fraction on the impact resistance of topcoat film.

\begin{tabular}{ccc}
\hline $\begin{array}{c}\text { Microcapsule Mass Fraction } \\
(\mathbf{\%})\end{array}$ & $\begin{array}{c}\text { Impact Resistance of } \mathbf{0 . 5 0} \\
\text { Core-Wall Ratio } \mathbf{( c m )}\end{array}$ & $\begin{array}{c}\text { Impact Resistance of } \mathbf{0 . 6 7} \\
\text { Core-Wall Ratio } \mathbf{( c m )}\end{array}$ \\
\hline 0 & $2.0 \pm 0$ & $2.0 \pm 0$ \\
1.0 & $4.0 \pm 0.1$ & $2.0 \pm 0$ \\
4.0 & $4.0 \pm 0.1$ & $2.0 \pm 0$ \\
7.0 & $4.0 \pm 0.1$ & $2.0 \pm 0$ \\
10.0 & $5.0 \pm 0.2$ & $2.0 \pm 0$ \\
13.0 & $5.0 \pm 0.2$ & $2.0 \pm 0$ \\
16.0 & $5.0 \pm 0.2$ & $2.0 \pm 0$ \\
20.0 & $5.0 \pm 0.2$ & $3.0 \pm 0$ \\
\hline
\end{tabular}


The adhesion of the samples is shown in Table 6. When the mass fraction of microcapsules is $1.0-7.0 \%$, the adhesion of microcapsules with 0.50 core-wall ratio is better. The adhesion decreased to grade 2 by increasing the mass fraction of microcapsules from $7.0 \%$ to $20.0 \%$. For the microcapsules with 0.65 of core-wall ratio, when the mass fraction in the coating is $1.0-4.0 \%$, the adhesion is grade 1 , and with the further increase in the mass fraction of microcapsules, the adhesion decreases to grade 2 . When the core-wall ratio of microcapsules is 0.50 and the mass fraction is less than $7.0 \%$, the topcoat film has better adhesion.

Table 6. Effect of the microcapsule mass fraction on the adhesion of topcoat film.

\begin{tabular}{ccc}
\hline $\begin{array}{c}\text { Microcapsule } \\
\text { Mass Fraction } \\
(\%)\end{array}$ & $\begin{array}{c}\text { Adhesion (Level) } \\
\mathbf{0 . 5 0} \text { Core-Wall Ratio }\end{array}$ & $\begin{array}{c}\text { Adhesion (Level) } \\
\mathbf{0 . 6 7} \text { Core-Wall Ratio }\end{array}$ \\
\hline 0 & $1 \pm 0$ & $1 \pm 0$ \\
1.0 & $1 \pm 0$ & $1 \pm 0$ \\
4.0 & $1 \pm 0$ & $1 \pm 0$ \\
7.0 & $1 \pm 0$ & $2 \pm 0$ \\
10.0 & $2 \pm 0$ & $2 \pm 0$ \\
13.0 & $2 \pm 0$ & $2 \pm 0$ \\
16.0 & $2 \pm 0$ & $2 \pm 0$ \\
20.0 & $2 \pm 0$ & $2 \pm 0$ \\
\hline
\end{tabular}

Figure 7 shows the FTIR spectra of the coating without microcapsule, with $4.0 \%$ and $16.0 \%$ of microcapsule (core-wall ratio of 0.67 ), with $4.0 \%$ and $16.0 \%$ of microcapsule (core-wall ratio of 0.50 ), respectively. At $1730 \mathrm{~cm}^{-1}$ there is a sharp characteristic peak of $\mathrm{C}=\mathrm{O}$, belonging to the transmittance of waterborne acrylic resin in the waterborne coating. With the change of the mass fraction of microcapsules, no peak disappeared or appeared in the infrared spectra of topcoats, which indicated that there was no difference in the composition of the coating [25].

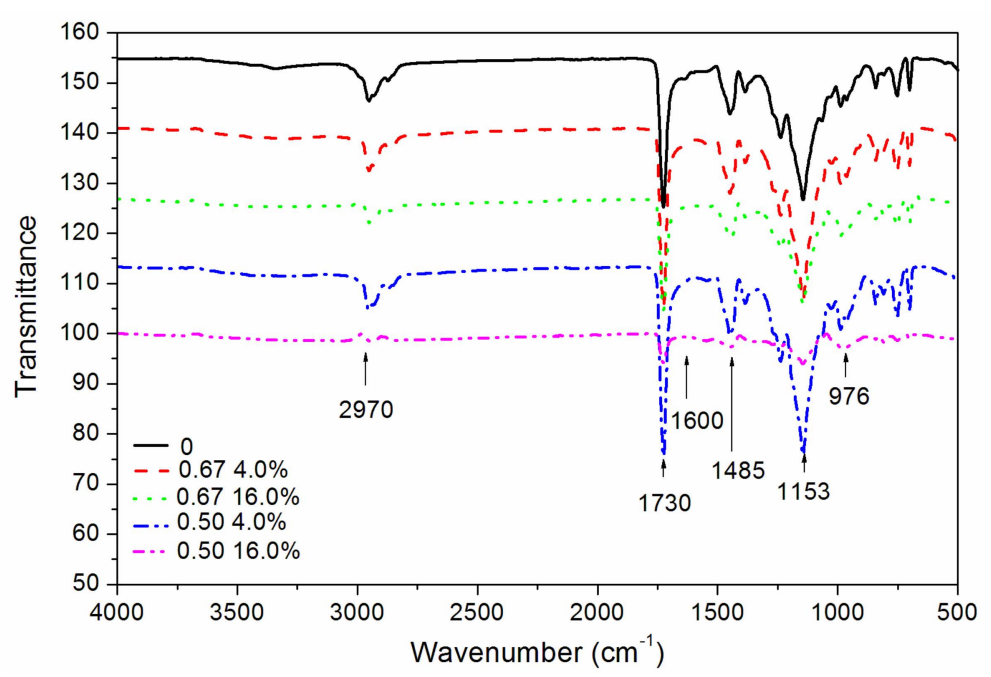

Figure 7. Infrared spectra of topcoats with different mass fractions of microcapsules and with different core-wall ratios.

\subsection{Ageing Resistance Test of Wood Coating}

After the UV ageing test, there were no cracks detected in the topcoat film. However, the color and gloss of the coating are changed, so the ageing resistance of the coating is analyzed by the color difference and the loss of light of the sample. Table 7 shows that as the mass fraction of the microcapsule increases, the color difference of the sample first decreases and then increases. It is predicted the microcracks of the coating after UV irradiation may be repaired in time by microcapsule, so the color 
difference of the coating was reduced. However, when the mass fraction of microcapsules is too high, the microcapsules will aggregate in the coating (Figure 4), which will probably reduce the ageing resistance. The change trend of the loss of gloss (Table 8) was consistent with that of the color difference, and the loss of gloss was the smallest when the mass fraction of the MF-coated epoxy microcapsules was $4.0 \%$. The decrease in gloss was due to the decrease in the reflection of light as the mass fraction of microcapsules increases.

Table 7. Change in the color difference after ultraviolet ageing resistance.

\begin{tabular}{ccc}
\hline $\begin{array}{c}\text { Microcapsule } \\
\text { Mass Fraction } \\
(\%)\end{array}$ & $\begin{array}{c}\text { Color Difference of 0.50 } \\
\text { Core-Wall Ratio }\end{array}$ & $\begin{array}{c}\text { Color Difference of 0.67 } \\
\text { Core-Wall Ratio }\end{array}$ \\
\hline 0 & $5.0 \pm 0.2$ & $5.2 \pm 0.1$ \\
1.0 & $3.2 \pm 0.2$ & $2.8 \pm 0$ \\
4.0 & $2.5 \pm 0.1$ & $1.7 \pm 0.1$ \\
7.0 & $2.7 \pm 0.1$ & $2.2 \pm 0$ \\
10.0 & $2.9 \pm 0.2$ & $2.6 \pm 0$ \\
13.0 & $3.8 \pm 0.1$ & $3.5 \pm 0.1$ \\
16.0 & $4.3 \pm 0.2$ & $3.8 \pm 0.1$ \\
20.0 & $4.5 \pm 0.2$ & $5.7 \pm 0.1$ \\
\hline
\end{tabular}

Table 8. Loss of gloss after ultraviolet ageing resistance.

\begin{tabular}{ccc}
\hline $\begin{array}{c}\text { Microcapsule } \\
\text { Mass Fraction } \\
(\%)\end{array}$ & $\begin{array}{c}\text { Loss of Gloss with 0.50 } \\
\text { Core-Wall Ratio (\%) }\end{array}$ & $\begin{array}{c}\text { Loss of Gloss with 0.67 } \\
\text { Core-Wall Ratio (\%) }\end{array}$ \\
\hline 0 & $6.1 \pm 0.2$ & $6.1 \pm 0.2$ \\
1.0 & $1.1 \pm 0$ & $1.3 \pm 0$ \\
4.0 & $0.1 \pm 0$ & $0.2 \pm 0$ \\
7.0 & $0.3 \pm 0$ & $0.5 \pm 0$ \\
10.0 & $0.6 \pm 0$ & $0.7 \pm 0$ \\
13.0 & $2.7 \pm 0.1$ & $2.6 \pm 0.1$ \\
16.0 & $4.4 \pm 0.2$ & $3.2 \pm 0.1$ \\
20.0 & $5.4 \pm 0.2$ & $4.1 \pm 0.2$ \\
\hline
\end{tabular}

\section{Conclusions}

Through SEM analysis, it was found that the microcapsules with 0.50 of core-wall ratio were more uniform and the surface was smoother. For the microcapsules with 0.50 of core-wall ratio, the resistance to impact of the film on basswood was enhanced with the increase in the concentration of microcapsules. The coating on the basswood with the microcapsule of 0.67 of core-wall ratio had low impact resistance and hardness. When the core-wall ratio of the microcapsules was 0.50 and the mass fraction was less than $7.0 \%$, the topcoat film on the basswood had good adhesion. With the increase in the mass fraction of microcapsules, the gloss of the film on the basswood decreased gradually. When the mass fraction of the MF-coated epoxy resin microcapsules was $4.0 \%$ and the core-wall ratio was 0.50 , the loss of gloss and color difference were the lowest. The ageing resistance of the topcoat film was improved at the mass fraction of microcapsules of $4.0 \%$. Taking the total analyses into account, when the mass fraction of the microcapsules with a 0.50 of core-wall ratio was $4.0 \%$, the comprehensive performance of the coating was better. The results will lay a technical foundation for the application of microcapsules in the healing of wood waterborne coatings.

Author Contributions: Conceptualization, methodology, validation, resources, data curation, writing-original draft preparation, supervision, X.Y.; data analysis, investigation, writing-review and editing, Y.C. All authors have read and agreed to the published version of the manuscript.

Funding: This project was partly supported by Graduate Research Innovation Program of Jiangsu Province (KYCX20_ 0888) and [General Program of Jiangsu Natural Science Foundation in 2020] (Project title: Study 
on the relationship between microstructure control of self-repairing coating and wood based on microcapsule technology).

Conflicts of Interest: The authors declare no conflicts of interest.

\section{References}

1. Pedaballi, S.; Li, C.C.; Song, Y.J. Dispersion of microcapsules for the improved thermochromic performance of smart coatings. RSC Adv. 2019, 9, 24175-24183. [CrossRef]

2. Dai, J.Y.; Ma, S.Q.; Liu, X.Q.; Han, L.J.; Wu, Y.G.; Dai, X.Y.; Zhu, J. Synthesis of bio-based unsaturated polyester resins and their application in waterborne UV-curable coatings. Prog. Org. Coat. 2015, 78, 49-54. [CrossRef]

3. Zhou, L.; Fu, Y.C. Flame-retardant wood composites based on immobilizing with chitosan/sodium phytate/nano- $\mathrm{TiO}_{2}-\mathrm{ZnO}$ coatings via layer-by-layer self-assembly. Coatings 2020, 10, 296. [CrossRef]

4. Xu, W.; Fang, X.Y.; Han, J.T.; Wu, Z.H.; Zhang, J.L. Effect of coating thickness on sound absorption property of four wood species commonly used for piano soundboards. Wood Fiber Sci. 2020, 52, 28-43. [CrossRef]

5. Herrera, R.; Muszynska, M.; Krystofiak, T.; Labidi, J. Comparative evaluation of different thermally modified wood samples finishing with UV curable and waterborne coatings. Appl. Surf. Sci. 2015, 357, 1444-1453. [CrossRef]

6. Zhang, S.W.; Yu, A.X.; Song, X.Q.; Liu, X.Y. Synthesis and characterization of waterborne UV curable polyurethane nanocomposites based on the macromonomer surface modification of colloidal silica. Prog. Org. Coat. 2013, 76, 1032-1039. [CrossRef]

7. Li, H.Y.; Cui, Y.X.; Li, Z.K.; Zhu, Y.J.; Wang, H.Y. Fabrication of microcapsules containing dual-functional tung oil and properties suitable for self-healing and self-lubricating coatings. Prog. Org. Coat. 2018, 115, 164-171. [CrossRef]

8. Xiong, X.Q.; Yuan, Y.Y.; Niu, Y.T.; Zhang, L.T.; Wu, Z.H. Effects of different treatments on surface activity of rice straw particleboard. Sci. Adv. Mater. 2020, 12, 289-295. [CrossRef]

9. White, S.R.; Sottos, N.R.; Geubelle, P.H.; Moore, J.S.; Kessler, M.R.; Sriram, S.R.; Brown, E.N.; Viswanathan, S. Autonomic healing of polymer composites. Nature 2001, 409, 794-797. [CrossRef]

10. Song, Y.K.; Kim, B.; Lee, T.H.; Kim, S.Y.; Kim, J.C.; Noh, S.M.; Park, Y.I. Monitoring fluorescence colors to separately identify cracks and healed cracks in microcapsule containing self healing coating. Sens. Actuators B Chem. 2018, 257, 1001-1008. [CrossRef]

11. Ataei, S.; Khorasani, S.N.; Neisiany, R.E. Biofriendly vegetable oil healing agents used for developing self healing coatings: A review. Prog. Org. Coat. 2019, 129, 77-95. [CrossRef]

12. Tasker, A.L.; Hitchcock, J.P.; He, L.; Baxter, E.A.; Biggs, S.; Cayre, O.J. The effect of surfactant chain length on the morphology of poly(methyl methacrylate) microcapsules for fragrance oil encapsulation. J. Colloid Interface Sci. 2016, 484, 10-16. [CrossRef] [PubMed]

13. Zhang, Z.Q.; Gao, Q.; Yang, J.M.; Wang, Y.; Yang, J.Y.; Zhang, X.; Feng, G.Z.; Cheng, Z.Q.; Wang, S.J.; Su, H.G. Fabrication and release behavior of nitrapyrin microcapsules: Using modified melamine-formaldehyde resin as shell material. Sci. Total Environ. 2020, 704, 135394. [CrossRef] [PubMed]

14. Ebrahimnezhad-Khaljiri, H.; Eslami-Farsani, R.; Chirani, S.A. Microcapsulated epoxy resin with nanosilica-urea formaldehyde composite shell. J. Appl. Polym. Sci. 2020, 137, 16. [CrossRef]

15. Dai, Y.; Wei, W.Q.; Zhang, J.W.; Anastaiia, A.; Chen, M.H. Effect of Si-based compound nanoparticles on anticorrosive properties of epoxy resin. J. Nanosci. Nanotechnol. 2020, 20, 4961-4970. [CrossRef]

16. Zhang, X.P.; Zhang, L.X.; Zhang, D.X.; Liu, S.S.; Wei, D.G.; Liu, F. Mechanism of the temperature-responsive material regulating porous morphology on epoxy phenolic novolac resin microcapsule surface. Colloid. Surf. Asp. 2020, 593, 124581. [CrossRef]

17. Liu, J.H.; He, Z.J.; Wu, G.H.; Zhang, X.Q.; Zhao, C.; Lei, C.H. Synthesis of a novel nonflammable eugenol-based phosphazene epoxy resin with unique burned intumescent char. Chem. Eng. J. 2020, 390, 124620. [CrossRef]

18. Yan, X.X.; Chang, Y.J. Investigation of waterborne thermochromic topcoat film with color-changing microcapsules on Chinese fir surface. Prog. Org. Coat. 2019, 136, 105262. [CrossRef]

19. Paints and Varnishes-Determination of Film Hardness by Pencil Test; Standardization Administration of the People's Republic of China: Beijing, China, 1998; pp. 1-3, GB/T 6739-2006. (In Chinese) 
20. Test of Surface Coatings of Furniture-Part 6: Determination of Gloss; GB/T 6739-2006; Standardization Administration of the People's Republic of China: Beijing, China, 2013; pp. 1-6. (In Chinese)

21. Jang, Y.; Lee, S.B.; Hong, J.H.; Chun, S.; Lee, J.; Hong, S. Synthesis of 2-aryl quinazolinones via iron-catalyzed cross-dehydrogenative coupling (CDC) between $\mathrm{N}-\mathrm{H}$ and $\mathrm{C}-\mathrm{H}$ bonds. Org. Biomol. Chem. 2020, 18, 5435-5441.

22. Shnawa, H.A.; Khalaf, M.N.; Jahani, Y. Thermal degradation, dynamic mechanical and morphological properties of PVC stabilized with natural polyphenol-based epoxy resin. Polym. Bull. 2018, 75, 3473-3498. [CrossRef]

23. Zhou, Y.C.; Chen, Z.Z.; Gong, H.J.; Chen, L.; Yu, H.Q.; Wu, W.L. Characteristics of dehydration during rice husk pyrolysis and catalytic mechanism of dehydration reaction with $\mathrm{NiO} /$ gamma- $\mathrm{Al}_{2} \mathrm{O}_{3}$ as catalyst. Fuel 2019, 245, 131-138. [CrossRef]

24. Xiong, X.Q.; Yuan, Y.Y.; Niu, Y.T.; Zhang, L.T. Research on the effects of roughness on the tactile properties of rice straw particleboard surface. Sci. Adv. Mater. 2020, 12, 795-801. [CrossRef]

25. Yan, X.X.; Qian, X.Y.; Lu, R.; Miyakoshi, T. Comparison and optimization of reactive dyes and coating performance on Fraxinus mandshurica veneer. Polymers 2018, 10, 1302. [CrossRef] [PubMed]

(C) 2020 by the authors. Licensee MDPI, Basel, Switzerland. This article is an open access article distributed under the terms and conditions of the Creative Commons Attribution (CC BY) license (http://creativecommons.org/licenses/by/4.0/). 